\title{
AS PERCEPÇÕES DE ACADÊMICOS DE ENFERMAGEM ACERCA DO LAZER
}

Vanessa Denardi Antoniassi Baldissera ${ }^{1}$, André Estevam Jaques² ${ }^{2}$ Larissa Angélica da Silva Philbert ${ }^{3}$, Sabrina CorralMulato $^{4}$, Janaína Luiza dos Santos 5 , Sonia Maria Villela Bueno ${ }^{6}$

RESUMO: O presente estudo teve como objetivo investigar e relatar a percepção sobre o lazer junto a acadêmicos de Enfermagem, permitindo que sejam lançados direcionamentos reflexivos sobre a relevância da formação profissional nesta temática. Foi realizada pesquisa qualitativa, por meio de questionário contendo questões abertas sobre a temática lazer, além de uma parte objetiva sobre questões relativas sobre o perfil dos participantes. Os dados foram interpretados e concluídos por meio de análise temática, após categorização das variáveis qualitativas identificadas. Através dessa pesquisa foi possível identificar e compreender que as opiniões e imagens sobre a temática lazer e a Enfermagem simbolizam a construção cognitiva individual destes conceitos, com percepções distintas de lazer na vida pessoal e profissional; e também notar entendimentos de senso comum nas concepções de lazer.

PALAVRAS-CHAVE: Atividades de lazer; Educação; Educação em saúde; Enfermagem.

\section{THE PERCEPTIONS OF NURSING ACADEMICS ON LEISURE}

ABSTRACT: This study aimed to investigate and give an account of perceptions on leisure among Nursing academics, permitting the production of reflexive directives on the relevance of professional training in this theme. The research was qualitative via a questionnaire with open-ended questions on the theme of leisure, as well as an objective part with questions related to the profile of the respondents. The data were interpreted and concluded through thematic analysis, after categorisation of the qualitative variables identified. Through this research it was possible to identify and understand that the opinions and images on the topic of leisure and Nursing symbolize the individual cognitive construction of these concepts, with perceptions of leisure in personal life and professional life being distinct; it was also possible to note understandings from 'common knowledge' in the concepts of leisure. KEYWORDS: Leisure activities; Education; Health education; Nursing.

\section{LAS PERCEPCIONES DE ACADÉMICOS DE ENFERMERÍA ACERCA DEL OCIO}

RESUMEN: El presente estudio tuvo como objetivo investigar y relatar la percepción sobre el ocio junto a académicos de Enfermería, permitiendo que sean lanzados caminos reflexivos acerca de la relevancia de la formación profesional en esta temática. Fue realizada investigación cualitativa, por medio de cuestionario con preguntas abiertas sobre la temática ocio, además de una parte objetiva sobre cuestiones referentes al perfil de los participantes. Los datos fueron interpretados y concluidos por medio de análisis temático, después de categorización de las variables cualitativas identificadas. Por medio de esa investigación fue posible identificar y comprender que las opiniones y imágenes sobre la temática ocio y la Enfermería simbolizan la construcción cognitiva individual de estes conceptos, con percepciones distintas de ocio en la vida personal y profesional; y también percibir entendimientos de sentido común en las concepciones de ocio.

PALABRAS CLAVE: Actividades de ocio; Educación; Educación en salud; Enfermería.

${ }^{1}$ Enfermeira. Doutora em Enfermagem Psiquiátrica. Professora do Centro Universitário de Maringá - CESUMAR e da Universidade Estadual de Maringá - UEM. Membro do Centro Avançado de Educação para a Saúde e Orientação Sexual - Educação Preventiva em Sexualidade, DST, AIDS, Drogas e Violência - CAESOS USP.

${ }^{2}$ Enfermeiro. Doutorando em Ciências pelo Programa de Pós-Graduação em Enfermagem Psiquiátrica da Escola de Enfermagem de Ribeirão Preto - EERP USP. Professor da Universidade Paranaense - UNIPAR. Membro efetivo do CAESOS e do Grupo de Estudos em Hipertensão Arterial - GEHA UNIPAR.

${ }^{3}$ Pedagoga e Psicopedagoga. Doutoranda em Ciências pelo Programa de Enfermagem Psiquiátrica da EERP USP. Professora do Ensino Fundamental I da Secretaria Municipal de Ribeirão Preto. Membro do CAESOS e GEHA.

${ }^{5}$ Fisioterapeuta. Doutoranda em Ciências pelo Programa de Enfermagem Psiquiátrica da EERP USP. Membro do CAESOS e GEHA.

${ }^{5}$ Enfermeira. Doutoranda em Ciências pelo Programa de Enfermagem Psiquiátrica da EERP USP. Membro do CAESOS e GEHA.

${ }^{6}$ Pedagoga. Doutora em Educação. Professora do Departamento de Enfermagem Psiquiátrica e Ciências Humanas e do Programa de Pós-Graduação da EERP USP. Líder do CAESOS e membro do GEHA.

\section{Autor correspondente:}

Vanessa Denardi Antoniassi Baldissera

Universidade Estadual de Maringá

Endereço: Av. Colombo, 5790 - 87020-000 - Maringá-PR-Brasil

E-mail: vanessadenardi@hotmail.com

Recebido: $01 / 02 / 11$

Aprovado: 18/05/11 


\section{INTRODUÇÃO}

A formação profissional em Enfermagem deve ser baseada, no Brasil, pelas Diretrizes Curriculares Nacionais que prevê uma "formação generalista, humanista, crítica, reflexiva", cidadã e ética. Esta visa capacitar e habilitar o profissional para a atenção integral à pessoa, à família e à coletividade, promovendo a saúde, na busca e intervenção de melhores alternativas em situações-problema ${ }^{(1: 1)}$.

A formação humanista dos estudantes de Enfermagem retrata um processo que envolve o compromisso com a vida, compreendendo a formação não como uma proposta de conformar ou modelar, mas sim como uma formação que vise o futuro profissional. Esta deve ser apreendida, internalizada com significância que qualifique o futuro profissional e o desenvolva como sujeito social, ativo, ético e solidário, dentro de um processo de humanização e de constante ação-reflexão e ação.

Formar um enfermeiro é primordialmente, colaborar com sua formação científica, consolidando a identidade social da Enfermagem, que é ciência e arte de cuidar de indivíduos, famílias e comunidades.

A Enfermagem é, uma atividade secular, que ganhou mérito científico através de Florence Nightingale $^{(2)}$. Sua fase moderna surgiu com a Fundação da Escola Nightingale de Treinamento para Enfermeiras, anexa ao Hospital Saint Thomas, em Londres, no século XIX. Através de Florence Nightingale afirmouse, portanto, uma nova concepção de Enfermagem, enraizada em princípios, ensino e arte do cuidado, afirmando-a como prática científica ${ }^{(3)}$.

Esta definição de Enfermagem implica numa descrição epistemológica ampla do termo cuidar:

Cuidar é um verbo que se refere à ação de assistir, ajudar ou facilitar ao outro indivíduo, com necessidades evidentes ou que podem ser antecipadas, que levam a melhorar ou aperfeiçoar uma condição humana ou modo de vida ${ }^{(4: 46)}$

O cuidado, portanto, é muito mais do que uma técnica, pois exige certo envolvimento com o outro, como afetividade e responsabilidade.

O cuidado possui uma abordagem filosófica já descrita desde os primeiros séculos, pela cultura grecoromana, considerando que cuidar é a essência da vida e, portanto, a Enfermagem, enquanto ciência que cuida, se apropria do mesmo status de existência ${ }^{(4)}$.

Florence Nightingale "idealizou uma enfermagem embasada em reflexões e questionamentos"(5:7) que pudessem diferenciá-la da medicina.

Apesar desta influência positiva das premissas de Florence que conduziram a Enfermagem para ações práticas, imediatistas, servis e não sistematizadas por longos anos, até que o desenvolvimento da ciência, a revolução feminista e as modificações sociais, econômicas, culturais e políticas, no mundo, provocaram a reflexão e percepção da necessidade de um corpo de conhecimento organizado.

Assim, surgiram as Teorias de Enfermagem, que passaram a ser elaboradas a partir da década de 1950, estabelecendo a definição do significado da Enfermagem, seu papel e seu método de trabalho. As teorias passaram a ser um caminho para a cientificidade da profissão $0^{(6)}$.

A enfermeira brasileira Wanda de Aguiar Horta foi a primeira a descrever a Teoria das Necessidades Humanas Básicas (NHB), redefinindo o conceito de Maslow para a Enfermagem e seu processo de trabalho, e constituindo o que se passou a conhecer como Processo de Enfermagem ${ }^{(7)}$, que valoriza e utiliza a estrutura teórica para aplicá-la na prática.

É importante salientar que a Enfermagem é uma ciência que envolve as ciências humana e as naturais, não podendo estar limitada à utilização de uma ou da outra e tampouco consideradas como elementos separados.

A Teoria de Horta ${ }^{(7)}$ classifica as necessidades humanas em três grandes grupos, distintos e interligados: necessidades psicobiológicas, necessidades psicossociais e necessidades psicoespirituais.

Considerando a constituição integral do ser humano - corpo, mente e espírito ${ }^{(7)}$, é legítimo afirmar que o lazer, de acordo com Horta, é um recurso vital para o ser humano. Por isso, sua natureza e formas de manifestação devem ser melhor investigadas.

O lazer aqui é entendido como

[...] um conjunto de ocupações às quais o indivíduo pode entregar-se de livre vontade, seja para repousar, seja para divertir-se, recrear-se e entreter-se ou, ainda para desenvolver sua informação ou formação desinteressada, sua participação social voluntária ou sua livre capacidade criadora, após livrar-se ou se desembaraçarse das obrigações profissionais, familiares e sociais ${ }^{(8: 25)}$.

Já é sabido da relação que existe entre lazer e qualidade de vida, visto que este se situa como atividade humana que favorece a socialização e a valorização da vida. De um modo ou de outro, o lazer está sempre 
associado à personalidade de um indivíduo e expressa a sua busca de satisfação pessoal e de prazer no tempo livre que detém. Portanto, é possível localizar o lazer dentro da pirâmide das necessidades prioritárias de Maslow - fisiológicas, segurança, relacionamento, estima e realização pessoal ${ }^{(8)}$.

A dimensão lúdica do ser humano não pode ser esquecida, porque o artístico e o lazer fazem parte do processo de sua formação, nas suas mais diversas formas de manifestação cultural podendo colaborar na formação de sujeitos mais éticos e solidários.

Dessa forma, para que o profissional de enfermagem realize a arte de cuidar é preciso que amplie seus conhecimentos sobre o lazer, expandindo sua compreensão sobre os fatores externos e internos que interferem no estilo de vida de cada pessoa e que podem influenciar na sua saúde ${ }^{(9)}$.

Um exemplo disso são as doenças crônicas, o estresse e/ou a vivência com situações estressantes e as próprias experiências pessoais que afastam ou aproximam o ser humano do lazer. Ao cuidar, o profissional precisa compreender que comportamentos e emoções reprimidos ou mal enfrentados podem ter implicações para a saúde, especialmente no que se refere aos eventos cardiovasculares ${ }^{(9)}$.

Para que o profissional de enfermagem possa atuar na integralidade da atenção, ele precisa compreender o lazer como parte das necessidades psicossociais e que a dimensão lúdica também faz parte dessa atenção. Por isso, é preciso pensar se o projeto político-pedagógico e o currículo abrangem essas questões durante a formação profissional.

Comumente se produz aquilo que se conhece, e somente se conhece o que se experimenta/vivencia num determinado cenário de ensino-aprendizagem; assim, pode-se construir uma sólida formação críticoreflexiva na medida em que percepções são contextualizadas, repensadas e apreendidas ${ }^{(10)}$.

É esperado que através do currículo escolar sejam perceptíveis a ordenação geral da instituição educativa, os objetivos e o perfil esperado dos estudantes através dos programas disciplinares, e que estes atuam como configurador da prática docente, além de projetos, estágios e atividades complementares, sendo visto não mais como uma atuação secundária e sim como uma ação reflexiva de transformação social ${ }^{(11)}$.

A elaboração de um currículo envolve técnicas, métodos, procedimentos, questões sociológicas, políticas e epistemológicas. Dessa forma é possível entender o currículo como vinculado a formas específicas e con- tingentes de organização da sociedade e de políticas da educação. Este estreito relacionamento entre currículo e sociedade confere ao mesmo um caráter de agente de mudança permanente.

Diante do exposto, o presente estudo teve como objetivo investigar e relatar a percepção sobre o lazer entre acadêmicos de Enfermagem participantes do Grupo de Estudos em Hipertensão Arterial (GEHA) da Universidade Paranaense (UNIPAR), de Maringá-Paraná, permitindo a reflexão sobre a relevância da formação profissional do enfermeiro nesta temática.

\section{METODOLOGIA}

Tratou-se de uma pesquisa de abordagem qualitativa , a qual "trabalha com o universo dos significados, dos motivos, das aspirações, das crenças, dos valores e das atitudes"(12:21), voltada para acadêmicos de Enfermagem de uma instituição da Região Noroeste do Paraná-Brasil, no ano de 2009, participantes do GEHA, no qual uma das linhas de pesquisa é o lazer junto à população hipertensa. A população-alvo constituiu-se de 15 acadêmicos de Enfermagem, no entanto, apenas 8 consentiram em participar.

A coleta de dados foi realizada no mês de abril de 2009, conduzida depois da assinatura do Termo de Consentimento Livre e Esclarecido, e após a certificação do Comitê de Ética em Pesquisa envolvendo Seres Humanos (CEPEH) sob protocolo n. 1000/2009; também houve autorização expressa da Direção da Instituição de Ensino, obtida pela assinatura do Termo de Permissão de Utilização dos Dados. Foram observados os preceitos éticos exigidos pela Resolução 196/96 do CONEP, garantindo aos participantes o anonimato, a desistência de sua participação voluntária em qualquer momento, de acordo com sua escolha e decisão, e a permissão para a utilização dos resultados para fins científicos.

Os participantes da pesquisa responderam a um questionário que versava sobre questões abertas com a temática "lazer", além de uma parte objetiva sobre questões relativas ao perfil de cada um: sexo, faixa etária, estado civil, ocupação/profissão, renda familiar, moradia e formação básica (fundamental e ensino médio). Optou-se pelo questionário para permitir livre exposição de ideias, visto que a relação de dependência entre pesquisados (acadêmicos) e pesquisador (professor) poderia se constituir em viés complicador de pesquisa. 
As questões abertas foram as seguintes: 1 . O que você pensa da vida, em geral? 2. E da sua? 3. O que você mais gosta de fazer? 4 . O que significa lazer para você, em sua vida pessoal? 5 . O que você faz para se distrair? 6. O que significa lazer para você, em sua vida profissional? 7. O que você faz para se distrair no trabalho? 8 . O que te dá mais satisfação na vida? 9. O que te dá menos satisfação na vida? 10. A temática qualidade de vida quanto à importância do lazer na vida da pessoa/grupo foi abordada na sua formação? 11. Você se sente preparado (competente) para trabalhar esse tema na sua prática profissional? Espaço livre para você se expressar sobre qualidade de vida.

Os dados foram interpretados e concluídos por meio da análise temática, após categorização das variáveis qualitativas identificadas, o que permite apreender o pensamento do autor sem nele intervir, para posteriormente realizar a interpretação textual.

As fases adotadas foram: 1) pré-análise - leitura flutuante; constituição do corpus (exaustividade, representatividade, homogeneidade; pertinência); formulação e reformulação de hipóteses (unidades de registro, de contexto, forma de categorizar); 2) exploração do material (categorias); 3) tratamento dos resultados e interpretação. Os significados emitidos formam a base da discussão das categorias para melhor compreensão a respeito da temática investigada.

\section{RESULTADOS}

Em relação ao perfil dos sujeitos, identificou-se que se trata de um universo feminino, com idade entre 21 e 27 anos, concluintes do Curso de Graduação em Enfermagem, a maioria com formação educacional básica em instituição pública, com participação no GEHA de três meses a um ano.

A Enfermagem como prática naturalizada feminina, constituindo-se provavelmente, em uma das profissões mais antigas, exercidas por mulheres. Podemos destacar vários motivos para isso, mas o aspecto cultural de que o cuidar é socialmente feito para as mulheres ainda se destaca. Além disso, os homens foram socialmente preparados para assumir cargos de liderança, o que na área da saúde, está atrelado à Medicina, mas hoje o profissional, independente de ser homem ou mulher, já assume posições de liderança no contexto da Enfermagem.

Os temas que emergiram das respostas foram agrupados em 11 categorias, conforme apresentado no quadro 1.
É importante observar que as percepções sobre lazer tiveram características distintas quando abordadas em relação à vida pessoal e à vida profissional, como se houvesse uma dicotomia entre pessoa versus profissional, ou uma segregação entre as práticas pessoais e práticas profissionais relativas ao lazer. Desta forma, o ambiente de trabalho, em geral, foi visto como local de neutralidade e indiferença para o lazer, denotando uma proibição velada desta prática conforme apresentado nas categorias 7, 8 e 11 .

\section{DISCUSSÃO}

É salutar, a afirmação de que o lazer tem papel fundamental para o relaxamento e alívio dos problemas advindos do contexto e do cotidiano das pessoas, tanto pessoal quanto profissionalmente ${ }^{(13)}$. No Brasil, a Constituição Federal Brasileira de 1988 incluiu o lazer como direito social, dever do Estado (no âmbito Nacional, Estadual e Municipal) e tem referências em estudo nesta temática ${ }^{(14)}$.

Nos últimos tempos, o lazer tem sido compreendido como um fenômeno relevante para a emancipação humana e cidadã, atrelado a estratégias de promoção da saúde que enfocam a qualidade de vida de cada pessoa, de acordo com o seu contexto cultural e social. É preciso entender o lazer não só como um direito ou necessidade mas, também, por sua articulação com as esferas sociais ${ }^{(15)}$.

Comumente o lazer é associado como contraposição ao trabalho, e que colabora para evitar o desgaste laboral, já que o trabalho repercute negativamente sobre a saúde mental ou na despersonalização e/ou alienação dos trabalhadores. Por outro lado, o bem-estar mental, como vimos em algumas respostas dos sujeitos da pesquisa, está associado à satisfação profissional, no sentido de que possibilita exercer atividades laborais que trazem prazer $^{(15)}$.

Embora se compreenda que as atividades de lazer relatadas centram-se em atividades socializantes (categoria 1) e que, contextualizadas pelo perfil dos sujeitos fosse o esperado, pois se trata de pessoas em fase adulta jovem e estudantes, observaram-se restrições de atividades de lazer. Por conseguinte, culturalmente a prática do lazer é, por muitas vezes, vista como sinônimo de atividades esportivas, reservada aos mais jovens e habilitados e que melhor se enquadram nos padrões de normalidade. Mas, esta não foi uma realidade observada entre este grupo, supostamente determinada pelas possibilidades de lazer que possuem no seu contexto social. 
Quadro 1 - Categorias sobre a temática lazer identificadas junto à acadêmicos de Enfermagem. Maringá, 2009

\begin{tabular}{|c|c|}
\hline CATEGORIAS & TRANSCRIČÃO DAS FALAS \\
\hline $\begin{array}{l}\text { 1. Atividades socializantes como principal lazer na vida } \\
\text { pessoal e profissional }\end{array}$ & $\begin{array}{l}{[. . .] \text { estar com a família, se relacionar com amigos [...] }} \\
\text { passeio, me reúno com amigos e família. } \\
{[\ldots . .] \text { sempre que posso organizo encontros com amigos. }} \\
{[\ldots . .] \text { de estar com pessoas que me alegram. }} \\
{[. . .] \text { saio com os amigos para, literalmente, jogar conversa }} \\
\text { fora. } \\
{[\ldots . .] \text { gosto de interagir com os pacientes. }} \\
{[. . .] \text { saber ter amizade com todos que você trabalha. }} \\
{[\ldots . .] \text { À medida que eu percebo que estou proporcionando }} \\
\text { lazer a uma pessoa que busca auxílio, consequentemente, } \\
\text { eu estou estabelecendo uma relação mais forte e dessa } \\
\text { maneira consigo me distrair através de uma conversa } \\
\text { informal. } \\
{[. . .] \text { confraternizações, comemoração de aniversários. }} \\
{[. . .] \text { conversar, tomar um café. }}\end{array}$ \\
\hline 2. Dicotomia entre querer e poder & $\begin{array}{l}{[. . .] \text { o que eu mais gosto de fazer, mas nem sempre consigo }} \\
\text { é conhecer lugares novos[...]. }\end{array}$ \\
\hline $\begin{array}{l}\text { 3. Distração como significado de lazer na vida pessoal } \\
\text { e profissional }\end{array}$ & $\begin{array}{l}\text { Algo que você faça pra distrair, lhe dar prazer. } \\
\text { Pra me distrair, procuro amigos. } \\
\text { [...] possuir um trabalho que lhe proporcione momentos } \\
\text { de descontração. } \\
{[\ldots . .] \text { momentos de descontração com a equipe que você }} \\
\text { trabalha. }\end{array}$ \\
\hline 4. Lazer como forma de diminuir estresse & $\begin{array}{l}\text { [...] lazer é utilizar mecanismos que te possibilitem um afas- } \\
\text { tamento temporário dos diferentes problemas e agentes } \\
\text { estressores que fazem parte do seu cotidiano. } \\
\text { Lazer significa diminuir o estresse. }\end{array}$ \\
\hline 5. Lazer como fator primordial para manter saúde & $\begin{array}{l}\text { Lazer significa momento imprescindivel que qualquer } \\
\text { ser humano necessita ter para conseguir levar uma vida } \\
\text { saudável de corpo e de mente. } \\
\text { Lazer é muito importante para a nossa saúde física e } \\
\text { mental. }\end{array}$ \\
\hline 6. Lazer como momento de fazer o que se gosta & $\begin{array}{l}\text { Lazer é momento que eu tenho de realizar coisas que eu } \\
\text { goste de fazer, sem preocupaçóes, sem pensar em datas, } \\
\text { horários. }\end{array}$ \\
\hline 7. Lazer como atividade que se opõe ao trabalho & $\begin{array}{l}\text { A pessoa se sente em paz, e pode descansar desse mundo } \\
\text { que é só trabalho. }\end{array}$ \\
\hline 8. Lazer profissional como doação & $\begin{array}{l}\text { [...] representa o quanto eu posso fazer para uma pessoa } \\
\text { que precisa mais que eu de determinada ajuda. No meu } \\
\text { trabalho, eu procuro proporcionar lazer aos usuários que } \\
\text { procuram o serviço. }\end{array}$ \\
\hline 9. Ócio como lazer & [...] até mesmo ficar em casa sem nada para fazer. \\
\hline 10. Gostar do que faz como lazer no trabalho & $\begin{array}{l}\text { Quando trabalhamos em algo que gostamos e sentimos } \\
\text { prazer em praticar, automaticamente se torna um lazer. }\end{array}$ \\
\hline $\begin{array}{l}\text { 11. Trabalho percebido como atividade improvável para } \\
\text { lazer }\end{array}$ & $\begin{array}{l}\text { [...] quando começar trabalhar de verdade, não sei como } \\
\text { farei para distrair do trabalho. }\end{array}$ \\
\hline
\end{tabular}


É lícito afirmar, que resquícios da história da Enfermagem ainda estão presentes na percepção destes sujeitos, quanto à prática da sua futura profissão e ao entendimento do lazer. Isto fica evidenciado ao relatarem que o exercício profissional traduz-se em ajuda (categoria 8), sinalizando a imagem da caridade nesta profissão, já tão demarcada na sua trajetória e que precisa ser superada, haja vista a práxis que a acompanha na atualidade. Ainda, que esta visão é tão real que se manifesta em proporcionar lazer ao outro (categoria 8) subjugando a relevância para o próprio profissional, sinalizando a necessidade de favorecer a saúde de quem é cuidado em detrimento de quem cuida.

A compreensão sobre o lazer é um processo através do qual o indivíduo desenvolve o entendimento de si mesmo e da relação deste com sua própria vida, e com a estrutura da sociedade em que vive.

Interessante também a persistência da percepção do lazer como ócio, numa aproximação conceitual de lazer como oposição a fazer algo. Esta imagem talvez esteja veiculada pela dicotomia entre trabalho versus não trabalho; desta forma, fazer algo simboliza trabalhar, o que se opõe ao lazer. Neste sentido, há uma concepção real do lazer, e talvez esteja presente nesta população pela intensidade das obrigações que realmente exigem momento de descanso e repouso como estratégia prazerosa ${ }^{(14)}$.

O lazer é uma ocupação na qual o indivíduo pode entregar-se de livre e espontânea vontade, seja para repousar, seja para divertir-se, recrear-se e entreter-se, ou ainda, para cultivar o convívio social com amigos e principalmente familiar.

Outra perspectiva que se deve atentar em relação ao lazer é que atualmente ele é tido como uma relação de consumo que se diferencia através das camadas sociais, que isso pode implicar desde as atividades realizadas, até ao posicionamento e entendimento em relação à vida e à sociedade em suas dimensões política, econômica, social, cultural, educacional, ambiental e da saúde.

Neste emaranhado de percepções lança-se olhares para as possíveis implicações para a prática profissional, para a saúde destes trabalhadores no exercício de sua profissão e sobre a formação profissional nesta temática. Parece notório assinalar que existe uma concepção enraizada na realidade social destes sujeitos em formação profissional e, ainda que tenham relatado que esta temática tenha sido abordada na trajetória acadêmica e que se sentem preparados para a prática profissional neste tema, evidenciou-se que as concep- ções estão mais centradas no senso comum, alicerçadas pelas vivências e experiências pessoais.

Neste sentido, parece que estas opiniões e imagens simbolizam a construção cognitiva individual destes conceitos, num movimento de apreensão da realidade. Esta realidade, entretanto, se manifestará nas práticas sociais, entre as quais as ações de Enfermagem e as ações pessoais, demarcando as atitudes que adotarão frente ao lazer, seja na vida pessoal, laboral, ou ao assistir o ser humano.

O lazer em alguns momentos é visto por duas correntes antagônicas que orientam a vivência. A primeira corrente enxerga o lazer como mercadoria, um entretenimento a ser consumido e que tem como finalidade contribuir para que as pessoas suportem as frustrações e as insatisfações crescentes geradas pelo tipo de vida que levam na sociedade. A segunda corrente concebe o lazer como prática social, historicamente gerada e que pode, na sua vivência, questionar os valores dominantes no nosso modelo de sociedade. Essa corrente valoriza a dimensão humana, cujas características são a alegria, a diversão, o respeito ao outro, a solidariedade, o prazer e a busca por uma melhor qualidade de vida $^{(16)}$.

Todavia, é imprescindível refletir sobre as condições de vida do ser humano, principalmente no âmbito profissional, pois, muitas vezes, depende dele a evolução de outros aspectos do indivíduo, como o lazer, a alimentação, a vestimenta e a participação de si e de seus familiares na sociedade e a dele próprio entendido como agente transformador, cidadão de direito e deveres.

\section{CONCLUSÃo}

Os sujeitos desta pesquisa demonstraram percepções distintas de lazer na vida pessoal e profissional, permitindo que se projetassem as repercussões desta visão, da mesma forma que se refletisse sobre a formação profissional nesta temática.

Espera-se que outros trabalhos possam ser conduzidos no sentido de melhor clarificar a relevância e aplicabilidade da formação do enfermeiro na temática lazer.

A dimensão lúdica do ser humano não pode ser esquecida, porque o artístico e o lazer fazem parte do processo de formação do homem, nas suas mais diversas formas de manifestação cultural, e pode colaborar na formação de sujeitos mais éticos e solidários.

Portanto, a cultura do lúdico pode contribuir para uma sociedade com uma visão mais ampla e humana, permitindo condições de vida com qualidade. 


\section{REFERÊNCIAS}

1. Ministério da Educação (BR). Conselho Nacional de Educação. Diretrizes curriculares nacionais do curso de graduação em enfermagem. Resolução n. 3, de 7 de novembro de 2001. Brasília; 2001.

2. Geovanini T. História da enfermagem: versões e interpretações. Rio de Janeiro: Revinter; 2009.

3. Almeida DV. O ensino da humanização nos currículos de graduação em enfermagem [dissertação]. São Paulo (SP): Universidade de São Paulo; 2007.

4. Crossetti MGO. Caring nursing actions of propedeutic and therapeutic nature and its interface with ot her professional actions. Rev Gaúch Enferm. [Internet] 2000;21(1) [acesso em 01 mai 2011]. Disponível: http:// seer.ufrgs.br/RevistaGauchadeEnfermagem/article/ view/4304/2267

5. Tannure MC, Gonçalves AMP. SAE- Sistematização da assistência de enfermagem: guia prático. Rio de Janeiro: Guanabara-Koogan; 2008.

6. Carvalho V. Caring, researching and teaching: meanings and implications of nursing practice. Rev Latino-Am Enfermagem. [Internet] 2004;12(5) [acesso em 01 mai 2011]. Disponível: http://www.scielo.br/pdf/rlae/v12n5/ v12n5a15.pdf

7. Horta WA. Processo de enfermagem. São Paulo: EPU; 2005.

8. Marcellino NC. Lazer e humanização. Campinas: Papirus; 2003.

9. Kochar MS, Woods KD. Controle da hipertensão: para enfermeiras e demais profissionais de saúde. São Paulo: Andrei; 1990.

10. Chirelli MQ, Mishima SM. Critical reflexive education of nurses from the nursing undergraduate program offered by the School of Medicine of Marília FAMEMA. Rev Latino-Am Enfermagem. [Internet] 2003;11(5) [acesso em 10 abr 2011]. Disponível: http:// www.scielo.br/pdf/rlae/v11n5/v11n5a03.pdf

11. Rodrigues MTP, Mendes Sobrinho JAC. Nurse-teacher: a dialogue with pedagogical education. Rev Bras Enferm. [Internet] 2007;60(4) [acesso em 01 mai 2011]. Disponível: http://www.scielo.br/pdf/reben/v60n4/a19.pdf

12. Minayo CS, Deslandes SF, Gomes R. Pesquisa social: teoria, método e criatividade. Petrópolis: Vozes; 2010.
13. Pereira MER, Bueno SMV. Lazer - um caminho para aliviar as tensões no ambiente de trabalho em UTI: uma concepção da equipe de enfermagem. Rev Latino-Am Enfermagem. [Internet] 1997;5(4) [acesso em 01 mai 2011]. Disponível: http://www.scielo.br/pdf/rlae/v5n4/ v5n4a10.pdf

14. Dumazedier J. Sociologia empírica do lazer: a dinâmica produtora do lazer. São Paulo: Perspectiva; 2008.

15. Bacheladenski MS, Matiello Júnior E. Contribuições do campo crítico do lazer para uma promoção da saúde. Ciên Saúde Colet. [Internet]. 2010;15(5) [acesso em 01 mai 2011]. Disponível: http://www.scielo.br/pdf/csc/ v15n5/v15n5a31.pdf

16. Marcellino NC. Lazer e educação. Campinas: Papirus; 2001. 